\title{
Pragmatic Level Of Language Personality In Social Networks
}

\author{
O. Akay \\ Dept. of Foreign Languages \\ Don State Technical University, \\ Rostov-on-Don, Russia \\ oksanaakay@gmail.com \\ A. Kalashnikova \\ Dept. of Foreign Languages \\ Don State Technical University, \\ Rostov-on-Don, Russia \\ kalashnikoffanna@gmail.com
}

\author{
I. Kalashnikov \\ Dept. of Economic Science \\ Rostov State Transport University \\ Rostov-on-Don, Russia
}

\author{
A. Golubeva \\ Dept. of Foreign Languages \\ Don State Technical University, \\ Rostov-on-Don, Russia
}

\begin{abstract}
The article is devoted to the communicative behavior of the language personality in social networks. The authors consider mechanisms by means of which the pragmatic level of the communicant's personality is realized. In the discourse of social networks, the basic element of the language pragmatism is not only the speech act. Communicative-active needs of the personality are determined by the peculiarities and conditions of the communicative situation, and the potentially communicative roles that are possible in this case are attached to it, as well as the hybrid of written and oral specifications of the discursive environment of social networks. Using such tool as a user name, the communicant creates a specific image of the author. The expected strategic development program is constructed by means of the user's name; the nickname bears the features of the user's real life, refracted in the pattern of his needs in the network environment. One of the main tools of influence at the pragmatic level becomes the orality of the discourse, sought by the user, which has the opportunity to subjectively expand the range of his own communicative freedom. Abbreviations, emoticons, symbols, orthoepic spelling, simplification of grammatical constructions are actively applied. Also, the language pragmatism of the linguistic personality is realized through emotional manipulation in the form of speech saturation with diminutive constructions.
\end{abstract}

Keywords - language pragmatism, linguistic personality, social network, computer-mediated communication, discourse, diminutive.

\section{INTRODUCTION}

The most important stage in the study of the language personality is the determination of the specifications of its pragmatic level realized in the communicative space. At the motivation level, the individual's language pragmatism is transmitted, that is, the result of the revealed motives and goals is the development of the personality. This level is realized in the communicatively active individual's needs. Language pragmatism as a subjective perception of the world by a person, embodied in the language frames, reflects psychological causal relationships and connections.
The pragmatic level is considered to be the highest in the device of the linguapersonalogical unit since the individual axiological data of the personality are collected in linguistic pragmatism [16].

Units are neither linguistic-oriented elements or words nor gnostically-oriented drill elements of the thesaurus: concepts, notions, descriptors. The units of the pragmatic level are oriented to the language pragmatism, and at this level, they are revealed in the communicative-activity individual's needs [1]. Yet to characterize such needs as strictly communicative is not correct, because needs do not exist only in this form. A linguistic individual tends to unite with the person in a global socio-psychological aspect at a pragmatic level, since «the linguistic personality is a personality expressed in the language and with the language reconstructed on the basis of linguistic means» [8].

The pragmatic level in the analysis of the linguistic personality shows a logical and mediated transition from the estimated component of the speech sphere to the component of comprehending real being by various factors, that is, this level in fact is the transition from speaking to action, from a speech act to a productive act. Discourse specificity of the pragmatic level consists of speech acts by people in social interaction in the purposeful use. The atomic unit of discourse-analysis of the pragmatic level is the verbal act [14].

It is also important that in the solid continuum of discourse, the levels of the linguistic personality are considered to be the solid whole and in fact an indivisible unit with no need for division and the formation of mutual borders.

However all levels of the linguistic personality taking into account the environment in which the personality exists require their own approaches to study. Thus, when analyzing the pragmatic level in the space of a social network, one should not lose sight of those extralinguistic factors that influence the development and existence of the individual. 
This is due to the fact that in the space of the social environment of virtual communication the main element of the language pragmatism is not only the speech act [11]. Communicatively active needs of the personality are attached to it and are conditioned by the peculiarities of the communicative situation and potentially communicative roles in this case. As a result of the Internet communication environment, the question about a special type of communication arose. The visual-written format, provided from the perspective of virtual space technology, is perceived by sight. It also provides the possibility of temporary remoteness between speech acts, which are considered to be a characteristic feature of written discourse [15].

\section{SOCIAL NETWORKS' LANGUAGE AS A LANGUAGE PERSONALITY EXPRESSION}

The empirical object of the research is records on personal pages and in public on the social network VKontakte as well as comments of users to them. The General Internet Corpus of the Russian language Webcorpora was used in the research; in addition, the material was obtained using the Yandex.Blogs service.

The applied method of analysis is a qualitative content analysis that allows describing the results of the study of the social networking environment, records and users' comments, demonstrating how to implement the pragmatic level of the communicant's language identity.

The key manifestation of a language personality needs is his or her self-presentation in that very communicative environment where he or she wants to get a quality of involvement. This aspect of the language pragmatism in social networks has two levels: pre-communicative self-presentation and records and self-presentation in a dialogue [5].

The social network field consists of entries and comments, as well as includes the following elements, which are means of pre-communicative self-presentation:

- username (nickname)

- avatar (pictogram-visual significance of the communicant),

- section «about» (personal information).

For the analysis of the communicant's social network language pragmatism, let us consider it worthwhile to pay special attention to such means of self-presentation as the username / nickname because it expresses the communicant's nominative competence. Through the way the communicant solves the problem of naming, the communicant's behavior assumed by the addressee is broadcast - and this completely proves the membership of the elements of pre-communicative self-presentation to the pragmatic level of the language personality [10].

The user name is rather a constant category. A nickname is most often chosen once, and then the image of the communicant develops in parallel to how the page in the social network is filled with content, and the author is growing over a certain network (and in recent years, along with the penetration of the Internet into real life offline) background. Thus, the username choice is a conditional bifurcation point: the decisive moment when the user selects a particular masked person. The nickname becomes a launching pad for the user's self-presentation [6].

As the communicant chooses the user's name, the role of the nickname in the person's linguistic pragmatism becomes obvious: it reflects the ideas of the linguistic personality as to what its message is and what the expected reaction to it is.

A nickname is an artistic image in the context of computer-mediated communication to even greater degree than that in real life: the user's name is the result of the communicator's meaningful creativity [4].

The expected strategic development program is laid in the user's name; the nickname bears the features of the user's real life, refracted in the spirit of his needs in the network environment. The communication and background experience, acquired over time, becomes an integral part of the nickname, generates in totality exactly the same discursive masked personality that can be talked about by examining the pragmatic level of the social network user language personality.

Accordingly if a communicant wishes to change his masked image for some reason, he often has to resort to a new page creation. The network communication principle, according to which any speech act caught on the Internet, becomes the public domain available in one or another form regardless of the time of its completion and the sphere of addressees' functions.

With the help of the nickname, the definition of the "native - strange" parameter is carried out. The most important component of the speech subculture of communities of linguistic individuals are precedent texts, and the precedent approach to nickname creation is actual [12].

The user name is a fictitious name; the communicative mask is a conditional shield behind which the real person is hiding. Using this mask-shield, the user does not only embody his linguistic pragmatism, but also carries out cognitive activities, trying himself in the roles inaccessible to him in ordinary life, so he realizes the function of cognition [7].

The nickname as an important element of the masked personality becomes one of the communicative means of implementing speech strategies that are the result of a communicative act. In anthropological linguistics, these strategies become a major segment of the pragmatic level of the language personality embodiment.

Pragmatism of the linguistic identity of the social network user is clearly embodied in the dialogue. One of the main instruments of influence here is the oral way of the discourse. The user seeks it, having an opportunity to subjectively expand the range of his own communicative freedom.

\section{EMOTIONS AS A WAY OF COMMUNICATION}

The phenomenon of using emoticons lays on the surface of this manipulative layer. Emoticon is an icon, a synonym for 
the smile concept, which consists of punctuation marks or graphic symbols. This term appeared when the notions "emotion" and "icon" were combined. Since virtual communication involves the absence of such vital for the expression of opinion and attitude phenomena as facial expressions and gestures, emoticons were introduced to solve this problem in online communication. Emoticons have some general rules of construction and are usually read when the image is rotated 90 degrees clockwise. Most emoticons are derived from two main ones :-) and :-(

Emoticons denote international concepts, so they do not reproduce current speech, do not reflect grammatical, phonetic, and other features of natural language.

How does emoticon affect the perception of the message? Emoticons are a direct tool for forming an impression of the author's position or his personality. Earlier when the field of Internet communication was just beginning to be formed (the main forms of early web communication were conferences and chats), researchers of computer-mediated communication conducted an analysis of the behavior of chat moderators [2]. As a result, it was revealed that the use of emoticons by moderators contributed to the perception by Internet users as more «dynamic», «friendly», «useful» and «inclined to communicate» compared to those who did not use smiles [13].

Here are the most popular emoticons:

:-) smile, joy

:-( sadness, sadness

: - | thoughtfulness or neutrality,

:-D laughter,: - \ puzzling or resentment

$:-0,=-\mathrm{O}, 8-\mathrm{O},:-[]$ surprise (open mouth)

: - [embarrassment

>: - D malicious laughter

: '- D strong laughter, laughter to tears

D-: strong anger, anger

;-) wink

$:-\mathrm{P},:-\mathrm{p},:-\mathrm{b}$ show the tongue

$:-*$ kiss

$:_{-}(,:$: (, : ' $(,: *$ ( cry

Also one should note that emoticons are gradually being transformed from derivative punctuation marks into readymade pictograms embedded in the program code. The meaning of emoticons remains the same.

It is necessary to note that abstract notions become widely spread in the emoticon language of social networks. There are icons symbolizing love (a heart image), anger (a devil image), being busy situation (a running figure) and so on [1].

100 users of the social network VKontakte were interviewed. Respondents were asked the following questions:

1. Do you use emoticons?
2. Do you use emoticons in posts?

3. Do you use emoticons in the comments?

4. What are the 3 most commonly used emoticons?

5. Why do you use emoticons?

The following results were obtained during the survey:

- 81 users of 100 use emoticons, while 4 use them «very rarely», 19 do not use emoticons ever;

- 53 users use emoticons in posts;

- 81 users use emoticons in comments - that is, all the users who answered "yes" on the first question;

- Among the most popular emoticons were :-) smile, joy (named by 79 users), :-( sadness, sadness (named by 75 users), ;-) wink (named by 55 users);

- the main reason for using emoticons named by users:

a) desire to more accurately express emotions ( 80 people);

b) desire to attract attention (44 users).

The sign status of emoticons at the time of their appearance was definitely iconic; they acted in two main roles: secondary signs and ideograms. As secondary signs, or substitute signs, they replaced not the object, but the primary sign, for example :-) - instead of the primary sign of the smile as an indicator of good mood and positive emotions. As ideograms, emoticons represented an idea or object without expressing its name. In both cases, the iconic motivation, based on association by similarity, was traced. However, as it can be argued on the basis of the above described survey by now the use of emoticons is constantly increasing due to the realization on the part of the communicants of the tendency to assimilate written communication to the oral type. $80 \%$ of respondents named motivation for the use of emoticons as desire to express emotions more accurately as in a live dialogue - that is intention to resemble oral speech.

\section{OTHER MEANS OF A LANGUAGE PERSONALITY EXPRESSION}

The striving of the linguistic personality towards the oral expression of the text is very widely manifested in the dialogue of comments. The authors of the comments are firstly exposed to the atmosphere, set by the "leader" - the author of the post. And secondly, being in conditions of mediated limitations of means and time (often leaving a comment to a post means that the author or other commentators will answer them, therefore in this case the principle " the faster you say the faster they answer" works) especially gravitate to the known oral language [3].

Specifically in the dialogue of comments abbreviations, emoticons, symbols, orthoepic spelling, simplification of grammatical constructions are actively applied. Let us consider for example the following communicative situation. The start post is devoted to online purchases:

"Tonight brought another order for Victoria Secret, of course, as always, all the essentials you can purchase. Could you ever live without pants with peacocks, with a $70 \%$ 
discount? OMG, sale be over soon. Here it is, the vegetable life of the nursing mother. Girlies, join, hit the sales of the family budget! I am a little amateur in the middle of my life".

The tendency to the oral language can be even more tangible in the comments:

- maxryta: I love this brand :))

- nucamb_no_necky: but I still can not get acquainted with outlet inet-shopping))) and thanx God))

- kengu_ry: I'm here, stunned by the instinct of self and child preservation, want to buy a rope ladder. Just in case that is on sale. That's it. Never found:)))

- zoe_dorogaya: For a hundred rubles I can hesitate offline, but here ... eh)))

Forgive me, please, but could you explain more in detail the technology of storing the rope ladder?)))

- kengu_ry: What if it's a fire?

GOD SAVE ME! +

- pitasha: I have also been thinking about the ladder for a long time ... but we live on the 8th floor, shit, I'm afraid there are no such stairs (()((

\section{- kengu_ry: Gagagagag !!! :)))}

So not only I am crazy :)))

- zoe_dorogaya: hohoho))) this is cool!

And by means of such linguistic tactics as transformation of written discourse into oral one, time is saved and communication is simplified: the time for thinking, writing, verifying the text is reduced, and by deliberate orthoepic twist a specific image of the author is created, the language personality manifests itself by means of such deviations from the norm.

Thus, one of the main communicative goals of the pragmatic level of the language personality is embodied, that is the receipt of a feedback.

The linguistic pragmatism of the linguistic personality is also productively realized through emotional manipulation. Speaking about the lexical emotional layer in social networks, special attention should be paid to such an aspect of communication as the use of diminutives. This is due to the hybrid of written-oral specifics of the social networks discursive environment.

Diminutives in social networks have a wide range of functions. Communicatively-pragmatic functions of diminutivity are based on excluding excessive categoricity from the speech because it interferes with the realization of fruitful communication. And the potential of the diminutives from the position of pragmatics is embodied through the opportunity to produce the necessary communicative effect and the establishment of effective interaction between communicants.

Diminutives are quite effective as a communicative mechanism providing the ability to produce the desired effect on the interlocutor. This is also true for the discursive environment of social networks. Despite the specifics and genre features, diminutivity here acts as a categorical antagonist leveling the language barrier of conflict situations that arise both from the addressee and from the addresser [6].

For example, the diminutive as a mechanism of the pragmatic apparatus successfully finds its application in the advertising discourse of social networks. The marketing field VKontakte is virtually unlimited: the audience of the service is made up of users of various ages and social status.

Emotional coloring in the description of any notion makes it possible to successfully promote goods and services:

\section{Dodo!}

Remember that keeping an eye on the figure with us is simple: the website lists the calories of each product".

A communicant using often diminutive constructions does not even inform the final recipient that he is involved in the speech situation of «advertising»:

'Fashionable material for velvet, T-shirt is dense, soft, pleasant to the body. T-shirt with a beautiful crimson hue, stylish pouch looks very, very nice".

Positive evaluation, clearly meant by the addresser, the implication of deformation of communication - all this prompts the addressee to pay attention to the offered goods.

Indeed, the dominant use of diminutives is given in evaluative-positive values at the cognitive level which are mainly fixed in dictionaries. However, diminutives are inherently enantiosemic. One diminutive word form can express not only a positive but also pejorative attitude towards something. For example, there is a confident transition of the word "ovulyashka" (referring to the so-called "Mamma" language, specific to the lexical communication environment of social networks) from the positive concept-sphere to the ironic-sarcastic one. A similar phenomenon is observed in speech situations, in which the words of the basic general lexicon are used. For example, let us compare the usage of the diminutives:

"Something so strictly pedantic suits you - neat haircutty and even a cutie little round glasses. A sort of all correctcorrect double correct".

Here, diminutive and affectionate suffixes emphasize the correctness of the choice of the recipient's style and have an emotionally positive meaning,

or:

"Fashionable hairstyle, fashion cutie little glasses, ducky lips, selfie in the mirrorry ... Hey guys what the ... ??"

In this case, the contemptuous use of diminutive constructions for the image and behavior of the object of speech is obviously traced.

Also, the negative meaning of the word can be given by adding a diminutive affection suffix to it, turning it into a diminutive «with a negative sign»: 
"There is such a type of people that say they are fairy humanees. Honestly I hate them. Do not digest! I'm sick of them.

Fairy humanees usually have everything in their heads decomposed into neat stamped shelves. If they made a remark - it means they are envious. Fairy humanees sincerely sculpt their posts about how with the sound of rain they wrap themselves in a warm fluffy plaid and warm their fingers with a cup of tea, thinking of themselves as super-originals in their little bloggies".

In the social networks environment, there is a phenomenon of "vanillity" - an image subcultural trend, cultivating romanticism, escapism, Internet addiction and illegibility in the ways of achieving goals. The lexeme "vanillie", formed from a completely neutral colored name of flavoring «vanilla», is a vivid example of a negative diminutive:

"I like to picture myself and others, but it does not mean that I'm vanillie or something like that",

"No vanillie, politics, snot, and so on. Just a recognition that we love our subscribers. Each of you".

That is, ironic and sarcastic connotations based on the main derivational values of diminutive affection suffixes can appear as a result of giving a quality of a diminutive to something large, or by bringing caresses into the characterization of something that is negated.

A desire to get a feedback forces the user to become "native" in the environment of potential recipients. The linguistic personality always aspires in one or another way to manifest membership in a particular subculture, social group or community. As a coded tactic of associating with a certain society, the communicant resorts to various verbal moves that can be triggers and can attract the attention of the target audience. In some cases, the use of diminutives is just a speech move.

The current linguistic and cultural situation in social networks is characterized with the phenomenon «grammarnazism». (grammar nazi) - Internet meme, ironic name and self-name of Internet communities that are characterized by extremely pedantic attitudes towards literacy. And one of the elements blamed for the current "grammarnazi" is the excessive use of diminutives. The diminutive in the speech of this group of communicants is used as an instrument of sarcasm and the diminutively caressing words used for their intended purpose are considered to be the markers of speech poverty and limitation. Diminutive preserves the pragmatic evaluation function, but acquires a shade of cynicism:

"You need a smart man here, and I'm always stirring up trouble. If not me, you would be more free: could smoke more, think not that much and travel faster";

Quite often this phenomenon is observed in the field of "gastronomy":

"So the real lagman is lamb. You can of course cook «pilaf» of chicken on a frying pan with ketchup and mayonnaisie";
"Saladies with a rich history. Every now and again you see the stories of the juniors about how their next masterpiece was created. Like that: I was sitting and I wondering what is the reason my sonny would not eat my meals - but would be so happy with vodka".

Also the diminutive, as a feature of expressing emotions in a relation to a phenomenon or a situation (relationship adopted precisely in the sociocultural environment to which the communicant belongs), can be referred to the categorial apparatus of protest discourse. For example, the use of the word "tenty" (meaning "The Public Chamber of the Russian Federation") is a pronounced signifier of a protest attitude towards the activity of this body, adopted in certain political and journalistic circles:

"The public tenty of the Russian Federation accused all Trump supporters of fascism and racism”.

However, more often the protest essence of the diminutive does not appear in sarcastic meaning. The diminutive words are becoming a kind of the escapism mechanism. In the present situation, when on the one hand, the situation in the world is becoming increasingly tense, financial and political crises are developing, which in turn contributes to the cancellation, typification and, to some extent, coarsening of the domestic and official language, and on the other hand, the society is more and more infantilized and the social and cultural phenomenon of the kid-alts is being actualized, the communicants are looking for an opportunity to escape from the reality to the world of virtual discourse and realize their communicative strategies.

In the scientific paradigm of anthropological linguistics, communicative strategies become an important segment of the realization of the pragmatic level of the language personality as a result of a communicative act.

The communicative strategy is defined as the type of behavior of one of the partners in the situation of dialogic communication, which is conditioned and correlated with the plan for achieving global and local communication goals [6]. At the same time, a communicative strategy is the result of organizing the speaker's behavior in accordance with a pragmatic goal-setting or intention. The communicative strategy is a part of communicative behavior or communicative interaction, in which a series of various verbal and non-verbal means is used to achieve a specific communicative goal, "the strategic result to which the communicative act is directed".

\section{Acknowledgment}

Analyzing the pragmatic level of the language personality in social networks, it is possible to identify the main communicative goals of the user of social networks:

- to express their views on a particular event or phenomenon;

- to receive the maximum resonance in reply to the stated point of view. 
Since one goal is a consequence of the other, it is obvious that the ultimate communicative goal in the social media discourse is the ultimate desire to receive a response. This is the dialogical essence of the discourse of the communicative space in question: one sentence automatically assumes a response to it in the form of another statement - and then along the chain.

Thus, the speech strategy of the language personality in social networks is aimed at achieving exactly this result: feedback-response which in its essence is potentially endless. Various pre-communicative and communicative mechanisms are applied for achieving these goals.

\section{References}

[1] O.M. Akay, "To the question of a category of number of abstract nouns in modern English", Philological science. Theory and practice, No. 6, 2016.

[2] A. Georgakopoulou, Narrative analysis and computer-mediated communication. Pragmatics of Computer-Mediated Communication, Berlin: Mouton de Gruyter, pp. 695-716, 2013.

[3] J. Giltrow, Genre and computer-mediated communication. Pragmatics of Computer-Mediated Communication, Berlin: Mouton de Gruyter, pp. 717-738, 2013.

[4] S. C. Herring, Relevance in computer-mediated conversation. Pragmatics of Computer-Mediated Communication,. Berlin: Mouton de Gruyter, pp. 245-268, 2013.

[5] A.A. Kalashnikova, "Realization of language person's main intension in blogosphere: feedback communicative strategy", Sovremennye problemy nauki i obrazovaniya, No. 6, 2012.

[6] A.A. Kalashnikova, I.V. Kovaleva, "Verbal-likeness as an Instrument of Influence in Communicative Blog-sphere", Humanities, Socialeconomic and Social Sciences, No. 5, 2013.

[7] N.N. Kanashina, "The Structure of the Functional-Semantic Microfield of the Diminutiveness in Russian, German, Mari and Chuvash Languages", Mediterranean Journal of Social Sciences No. 6-3, pp. 199204, 2015.

[8] M.N. Krylova, "Ways of expression of emotions in social networks", Philologia i literaturovedenie, No. 1, 2017.

[9] R. Lambert, "Diminutive reduplication in government phonology", Revista de Estudos da Linguagem, No. 12(1), pp. 88-113, 2004.

[10] C.R. Pinheiro, An Introduction to Social Network Analysis. Social Network Analysis in Telecommunications. Hoboken: John Wiley \& Sons. 215 p., 2015.

[11] R.E. Rice, Network analysis and computer-mediated communication systems. Advances in social network analysis, Thousand Oaks: Sage, pp. 167-203, 1994.

[12] R. Tarsiero, Linguistics of Computer-Mediated Communication. Handbook of Research on Computer Mediated Communication, New York: Hershey, pp. 983-1001,2004.

[13] K.Thilakarathna, S.Seneviratne, K. Gupta, M. A. Kaafar, \& A. Seneviratne, "A deep dive into location-based communities in social discovery networks", Computer Communications, vol. 100, pp. 78-90, 2017.

[14] T. Virtanen, Performativity in computer-mediated communication. Pragmatics of Computer-Mediated Communication, Berlin: Mouton de Gruyter, pp. 269-290, 2013.

[15] B. Wellman, The Development of Social Network Analysis: A Study in the Sociology of Science. Vancouver, CA: Empirical Press. 218 p., 2008.

[16]H. G. Widdowson, Discourse analysis. Oxford: Oxford Univ. Press. 185 p. 2008. 